\title{
Inference for econometric modeling in antidumping, countervailing duty and safeguard investigations - Erratum
}

\author{
JAMES J. FETZER * \\ US International Trade Commission, Applied Economics Division, Washington, DC \\ doi:10.1017/S147474560999005X
}

Volume 8 (2009) Number 4

Pages 545-557

Owing to an unfortunate technical error, the following footnote was omitted from the first page of the published version of this paper:

* Email: james.fetzer@usitc.gov

This paper represents solely the views of the author and does not represent the views of the U.S. International Trade Commission or any of its Commissioners. I would like to thank John Benedetto, Devry Boughner, Nannette Christ, Cindy Cohen, Judy Dean, Cathy DeFilippo, Alan Fox, John Giamalva, Mitch Ginsburg, Bob Koopman, Craig Thomsen, Steve Trost, James Worth, seminar participants at the Western Economics Association International Meetings, the editor, and two anonymous referees for their invaluable comments and suggestions. The author is solely responsible for any remaining errors.

The correct version of this paper can be found on the following pages.

This correction does not substantially alter the content of this article and citations should use the original volume, issue and page numbers.

\section{Reference}

Fetzer, James F. (2009), 'Inference for econometric modeling in antidumping, countervailing duty and safeguard investigations’, World Trade Review, 8(4): 545-557. 


\title{
Inference for econometric modeling in antidumping, countervailing duty and safeguard investigations
}

\author{
JAMES J. FETZER* \\ US International Trade Commission, Applied Economics Division, Washington, DC
}

\begin{abstract}
This paper examines how to make inferences from econometric models prepared for antidumping, countervailing duty, and safeguard investigations. Analysis of these models has typically entailed drawing inferences from point estimates that are significantly different from zero at a fixed level of confidence. This paper suggests a more flexible approach of drawing inferences using confidence intervals at various significance levels and reporting p-values for the relevant test of injury. Use of confidence intervals and p-values to identify insights and data patterns would have more impact on USITC trade remedy determinations than definitive conclusions about injury based on whether estimates are statistically significant.
\end{abstract}

\section{Introduction}

This paper suggests an appropriate framework for making inferences from econometric models prepared for of antidumping, countervailing duty, and safeguard investigations (trade remedy investigations) in the US. This approach is also appropriate for econometric models in other legal proceedings or even general research. For example, the approach could be used for econometric models that have been designed to provide evidence of conspiracy, the presence of market power, the nature or relevant markets, the likelihood of anticompetitive effects, the fact of injury, and the quantification in antitrust proceedings. ${ }^{1}$

'Injury' in trade remedy investigations is defined by the laws governing the investigation. For antidumping and countervailing duty investigations, 'material injury' is defined as 'harm which is not inconsequential, immaterial, or

\footnotetext{
* Email: james.fetzer@usitc.gov

This paper represents solely the views of the author and does not represent the views of the U.S. International Trade Commission or any of its Commissioners. I would like to thank John Benedetto, Devry Boughner, Nannette Christ, Cindy Cohen, Judy Dean, Cathy DeFilippo, Alan Fox, John Giamalva, Mitch Ginsburg, Bob Koopman, Craig Thomsen, Steve Trost, James Worth, seminar participants at the Western Economics Association International Meetings, the editor, and two anonymous referees for their invaluable comments and suggestions. The author is solely responsible for any remaining errors.
}

1 ABA Section of Antitrust Law (2005), 1-3. 
unimportant'. ${ }^{2}$ The law directs the US International Trade Commission (USITC) to consider (1) the volume of imports of the subject merchandise, (2) the effect of imports of that merchandise on prices in the United States for domestic like products, and (3) the impact of imports of such merchandise on domestic producers of domestic like products in the context of production operations within the United States. ${ }^{3}$ Global safeguards require that the injury or threatened injury be 'serious' and that the increased imports must be a 'substantial cause' (important and not less than any other cause) of the serious injury or threat of serious injury. ${ }^{4}$ Consequently, this paper will focus on the impact of changes in imports on the price for which the domestic good is sold, one of several possible proxies for injury.

Inferences made from these models in many cases have been limited to testing whether coefficients are statistically different from zero and using point estimates in simulations. For example, Prusa and Sharp (2001) infer that the impact of subject imports on the price of domestically produced cold-rolled steel is close to zero because their estimate of the impact is not statistically different from zero. However, a standard two-tailed confidence interval constructed from their estimates is so wide that little about the magnitude or even the sign of true parameter can be inferred from their estimate.

This paper suggests an approach to inference that accounts for the precision of the estimate by reporting confidence intervals and p-values. With this approach, estimates which are found to be statistically insignificant are not discarded or ignored and ones which are found to be significant are not necessarily treated as precise estimates.

\section{Typical use of inference}

Incorporating standard errors into inference is typically done using hypothesis tests or confidence intervals. A hypothesis test uses a parameter's point estimate and standard error to test whether the true value of the parameter is different from a hypothesized value. ${ }^{5}$ The most typical hypothesis test is whether the true value of the parameter is equal to zero, commonly, but loosely, referred to as the test for statistical significance. Results from a hypothesis test can be reported either by assuming a level of significance and reporting whether or not the hypothesis is rejected or by reporting the p-value, which is the lowest significance level at which the hypothesis could be rejected. A confidence interval uses the parameter's point

2 Section 771(7) of the Act (19 USC. $\S 1677(7)$ ).

3 USITC (2007), II-28.

4 Section 201 of the Trade Act of 1974. See http://www.usitc.gov/trade_remedy/trao/us201.htm.

5 Strictly, the researcher postulates a value for the parameter-a so-called null hypothesis - and asks whether the estimated value could have arisen by chance if it were true. If the estimate is sufficiently different from the postulated value (e.g. it could have arisen with a less than $5 \%$ probability), the null hypothesis is rejected in favor of an alternative hypothesis. The latter might be that the parameter is not equal to the postulated value or that it differs from the postulated value in a particular direction. 
estimate and standard error to construct a range of probable values of the true parameter value.

Confidence intervals and p-values are more flexible uses of inference than testing whether a hypothesis is rejected or not at a fixed level of significance. P-values assume a hypothesis, but can be evaluated at various levels of confidence, while confidence intervals use a fixed level of confidence, but can be used to evaluate various hypotheses. The ABA Section of Antitrust Law (2005) indicates that courts should avoid relying solely on sharply defined statistical tests since there is some arbitrariness in choosing a hypothesis. ${ }^{6}$ Instead, they encourage reporting the p-value or a confidence interval over reporting whether a hypothesis has been rejected or not because it conveys useful information to courts regardless of whether the hypothesis is rejected. ${ }^{7}$

The usual test for statistical significance is an example of a two-tailed test because the null hypothesis can be rejected by observing values that are either sufficiently greater or sufficiently smaller than zero. A one-tailed tailed test, on the other hand, seeks to reject the null with an alternative that the true parameter differs in a particular direction - positive or negative - and is conducted by asking whether the estimate is, respectively, sufficiently greater or sufficiently smaller than the value in the null hypothesis. An example of a one-tailed test would be testing whether a parameter is positive. Although not used as commonly as one-tailed hypothesis tests, one-sided confidence intervals that focus on whether the true parameter value is positive or negative can also be constructed. ${ }^{8}$ Since economic theory usually suggests the sign of the impact of a potential cause of injury, onetailed hypothesis tests are usually appropriate for making inferences about injury analysis. ${ }^{9}$

Much economic research makes inferences based on whether a point estimate is statistically significant. Zilak and McCloskey (2004) finds that most articles published in one of the top journals in economics (the American Economic Review) during the 1980s and 1990s - do not distinguish between statistical and economic significance. They point out that even though statistical significance is neither necessary nor sufficient for a finding to be economically important, an overwhelming majority of economists believe that statistical significance is necessary and that a majority believe it is sufficient.

\section{Typical models of injury}

It is important to understand the structure of a typical model of injury when making inferences. Typically, a price, volume, or profit margin has been used as 
the proxy for the effect of subject imports, while the proxy for the domestic like products is typically the price of the domestically produced good. Most models also include control variables for other factors affecting imports, including prices of substitute goods and downstream goods, general economic conditions, input prices, and capacity utilization. Some papers formally derive either reduced form or structural supply and demand equations, while others assume linear or log-linear supply and demand equations. For example, Charles Rivers Associates (2000) estimate a reduced form equation where the price of domestically produced Expandable Polystyrene Resins (EPS) depends on a one-month lag of the prices of US produced, subject imports, and non-subject imports of EPS; a one-month lag of the price of styrene, and residential construction activity. ${ }^{\mathbf{1 0}}$

It is not clear what the proxy for imports should be in safeguard investigations, since factors such as demand may affect imports. Some indicate that the total change in imports should be considered when estimating the impact of imports, while others indicate that only changes in imports resulting from the change in foreign excess supply should be used. For example, Pindyck and Rotemberg (1987) include all changes in imports when estimating injury, while Grossman (1986) measures imports as any exogenous shift in foreign excess supply, ignoring changes in import supply resulting from changes in price in the US or other factors inside the US market that may affect import demand. ${ }^{11}$

The appropriate test for injury depends on the statute governing the investigation. In antidumping and countervailing duty investigations in the US, the relevant standard is that the impact from subject imports rises to the level of material injury. Since material injury is not quantitatively specified by statute, some impacts greater than zero could be found to not be injurious. Therefore, confidence intervals allow for flexibility in determining how large the impact from subject imports is. For global safeguard investigations in the US, the relevant standard is that injury from imports is important and not less than any other cause of injury (this is also referred to as serious injury). Therefore, it seems to be appropriate to test both whether the estimated injury attributed to imports is important and whether it is greater than the estimated injury attributed to other potential causes of injury in safeguard investigations, as Grossman (1986) does.

\section{Examples of inference of injury}

Some models prepared for trade remedy investigations use p-values or confidence intervals in analyzing injury. For example, Grossman (1986) uses p-values in making inferences on the impact of several potential causes of injury for the US steel industry and finds that the impact is sensitive to the period examined. ${ }^{12} \mathrm{He}$

10 All studies treat either the volume or price of subject imports as exogenous.

11 See Rousslang (1988) and Irwin (2003) for a further discussion of this issue.

12 His model of the steel industry was prepared for the 1984 US steel safeguard investigation. 
finds that there is less than a $1 \%$ probability that employment losses attributable to import competition are greater than those attributable to a general secular trend between 1976 and 1983, but that the probability that these losses are greater increases to more than $20 \%$ between 1979 and $1983 .{ }^{13}$ Therefore, we would expect other analyses of injury that focus on data for 1976 to 1978 to provide better evidence of injury than analyses that focuses on data for 1979 to 1983.

Inferences for models prepared for many other trade remedy investigations rely on whether a particular hypothesis is rejected or not at a fixed level of significance. For example, Prusa and Sharp (2001) indicate that both the statistical insignificance and the small magnitude of their estimate of the impact of the price of subject imports on the price of domestically produced cold-rolled steel is evidence that subject imports did not injure the domestic industry. ${ }^{14}$ Their point estimate implies that a $10 \%$ decrease in the price of subject imports would lower prices for domestically produced cold-rolled steel by about $0.2 \%$. However, the estimated coefficients and standard errors indicate that their model does not estimate either the sign or magnitude of the coefficients with a high level of confidence, adding a great amount of uncertainty to their estimated impact of subject imports.

\section{Confidence intervals and $p$-values for econometric estimates of injury}

Table 1 reports estimates from a variety of models prepared for trade remedy investigations. Typically these models used the price of the domestically produced product as the proxy for injury. Assuming that subject imports and the domestically produced product are substitute products to some extent, increases in the price of subject imports should increase the price of the domestically produced product, while an increase in the volume of subject imports should decrease the price of the domestically produced product. Increases in the profit margin for upstream goods should increase the price of the domestically produced product (and also the price of subject imports). Therefore, coefficients of the effect for subject import prices and profit margins of upstream goods on the domestic price are expected to be positive and coefficients for subject import volumes are expected to be negative.

In addition to showing the reported estimated coefficients and standard errors, Table 1 also provides the test statistic for the test that the coefficient is positive (for estimates that should be positive) or negative (for estimates that should be negative), and my calculations for the p-value of this hypothesis and both

13 The secular trend includes labor-saving technological changes, faster than average growth of employment and productivity in the high-technology and service sectors, and a slow decline in the demand for domestic steel is not explained by either relative price or real income movements. Specifically, the paper compares job losses in January 1976 and January 1979 to average job losses during August to October 1983 Grossman (1986: 221-222, table 2).

14 Prusa and Sharp (2001: table 1). Their model of the cold-rolled steel industry was prepared for the US antidumping investigation of that industry during 1999 and 2000. 
one-sided and two-sided confidence intervals at the $95 \%$ level of confidence. ${ }^{15}$ Both one-sided and two-sided confidence intervals show that even for estimates that are significantly different from zero, the width of the confidence interval can vary widely. The widths of these confidence intervals imply that any simulation using these estimates may also vary widely when the standard errors are accounted for. For example, the coefficient which has the highest t-statistic (5.638) in Table 1 (the impact of the hot-rolled margin on the price of domestically produced coldrolled steel ('B' specification)) for Hausman (2001) has a two-sided confidence interval which varies from 0.167 to 0.344 .

Table 1 demonstrates that statistically significant estimates can sometimes be stronger evidence that the impact is smaller than estimates that are not statistically significant. For example, even though the estimated impact of subject imports from Carter (2005) is statistically significant while a similar estimate from Tilley (2005) is not, the much smaller standard error for the Carter (2005) estimate yields stronger evidence that the impact of imports is small. ${ }^{16}$ The Carter (2005) estimate indicates that there is a $95 \%$ chance that the actual impact of a $1 \%$ increase in subject imports of frozen concentrated orange juice is a decrease in the futures price by less than $0.015 \%$ (from $-0.015 \%$ to $+\infty$ ), while the estimate from Tilley (2005) indicates that a $1 \%$ increase in subject imports would lower the futures price by less than $0.223 \%$ (from $-0.223 \%$ to $+\infty$ ), with $95 \%$ confidence.

Table 1 also demonstrates that more precise estimates sometimes provide stronger evidence of small impacts than smaller point estimates with larger standard errors. For example, consider elasticities from Prusa and Sharp (2001) and Prusa (2002) which both estimate the impact of the price of subject imports on the US cold rolled steel industry. Despite having both a larger estimated coefficient and t-statistic, the estimate from Prusa (2002) can be used to say that actual elasticity is less than 0.153 (from $-\infty$ to 0.153 ), with $95 \%$ confidence, while the estimate from Prusa and Sharp (2001) only indicates that the actual elasticity is less than 0.208 (from $-\infty$ to 0.208 ), with the same level of confidence.

\section{Accounting for standard errors in simulations}

It is important to report any simulations using confidence intervals and p-values, since relying solely on point estimates provides a false sense of precision.

15 The critical values from the $\mathrm{t}$-distribution used to calculate $\mathrm{p}$-values and interval estimates assume an infinitely large sample. If the actual sample sizes had been used in calculating the critical values from the t-distribution, the p-values may have been slightly larger and the confidence intervals would have been slightly wider in some instances. In some of the studies, the standard error of the estimate was not reported but derived from the estimated coefficient and the t-statistic.

16 The elasticity from Carter (2005) was estimated using the volume of Brazilian imports of frozen concentrated orange juice, while the elasticity from Tilley (2005) was estimated using the volume of Brazilian imports of both frozen concentrated and not from concentrate orange juice. Both estimates use the futures price of frozen concentrated orange juice. 
Table 1. Summary of point estimates and standard errors from selected econometric models ${ }^{1}$

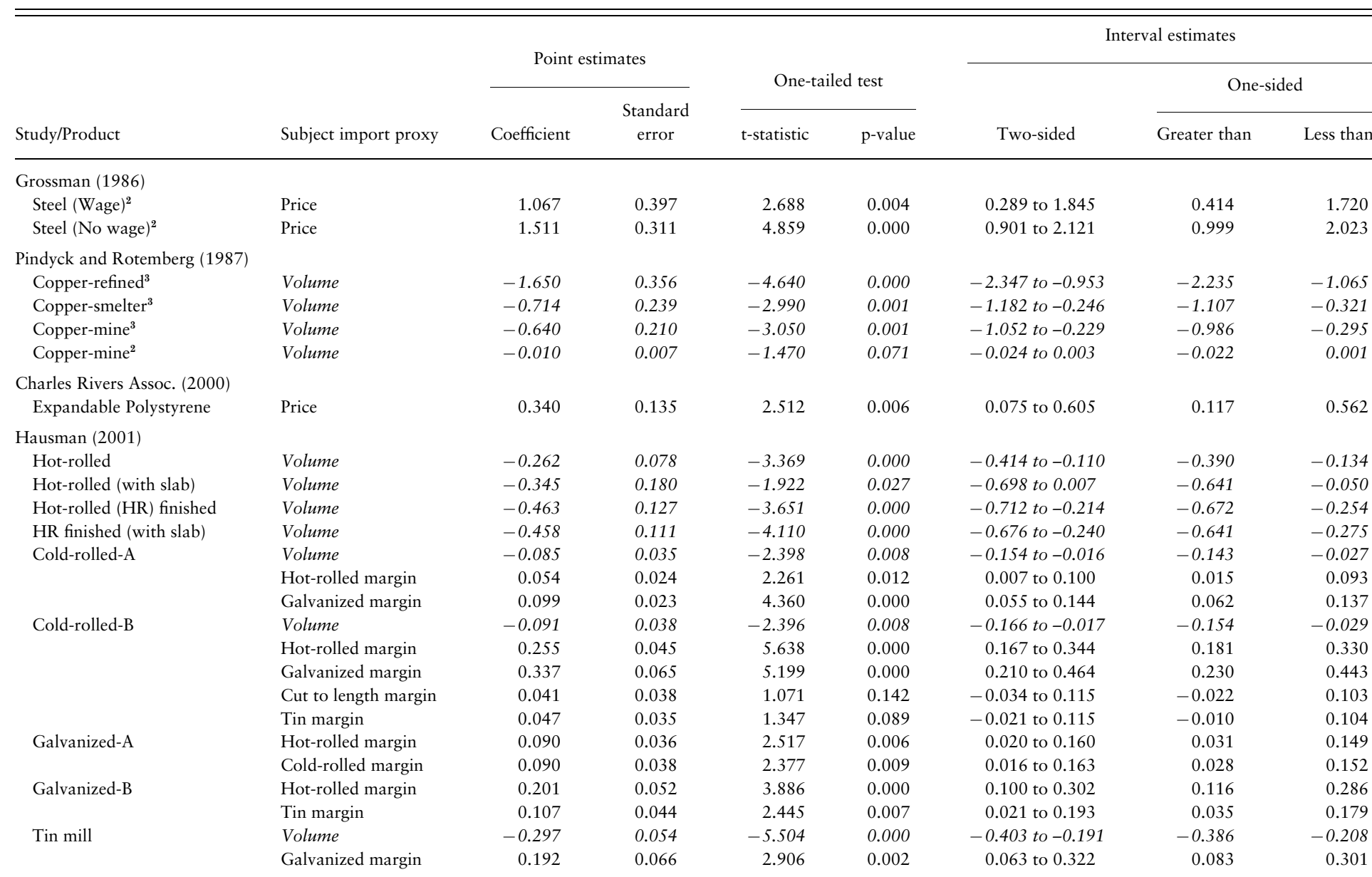




\begin{tabular}{|c|c|c|c|c|c|c|c|c|}
\hline Cut to length plate & Volume & -0.016 & 0.005 & -3.160 & 0.001 & -0.026 to -0.006 & -0.024 & -0.008 \\
\hline Cut to length plate & Hot-rolled margin & 0.043 & 0.010 & 4.310 & 0.000 & 0.024 to 0.063 & 0.027 & 0.060 \\
\hline \multicolumn{9}{|l|}{ Prusa $(2001 a, b, c)$} \\
\hline Hot-rolled-A & Price & 0.254 & 0.133 & 1.910 & 0.028 & -0.007 to 0.515 & 0.035 & 0.473 \\
\hline Hot-rolled-B & Price & 0.183 & 0.133 & 1.376 & 0.084 & -0.078 to 0.444 & -0.036 & 0.402 \\
\hline Cold-rolled-A & Price & 0.018 & 0.081 & 0.222 & 0.412 & -0.141 to 0.177 & -0.115 & 0.151 \\
\hline Cold-rolled-B & Price & -0.006 & 0.082 & -0.073 & 0.529 & -0.167 to 0.155 & -0.141 & 0.129 \\
\hline Cold-rolled-C & Price & 0.031 & 0.079 & 0.392 & 0.347 & -0.124 to 0.186 & -0.099 & 0.161 \\
\hline Cold-rolled-D & Price & 0.010 & 0.080 & 0.125 & 0.450 & -0.147 to 0.167 & -0.122 & 0.142 \\
\hline Galvanized-B & Volume & 0.036 & 0.024 & 1.500 & 0.933 & -0.011 to 0.083 & -0.003 & 0.075 \\
\hline Galvanized-A & Price & 0.018 & 0.130 & 0.138 & 0.445 & -0.237 to 0.273 & -0.196 & 0.232 \\
\hline Galvanized-B & Volume & -0.009 & 0.017 & -0.529 & 0.298 & -0.042 to 0.024 & -0.037 & 0.019 \\
\hline \multicolumn{9}{|l|}{ Prusa and Sharp (2001) } \\
\hline Cold-rolled & Price & 0.022 & 0.113 & 0.195 & 0.423 & -0.199 to 0.243 & -0.164 & 0.208 \\
\hline \multicolumn{9}{|l|}{ Hausman (2002) } \\
\hline Cold-rolled & Volume & -0.157 & 0.052 & -3.037 & 0.001 & -0.259 to -0.056 & -0.243 & -0.072 \\
\hline \multicolumn{9}{|l|}{ Prusa (2002) } \\
\hline Cold-rolled & Volume & -0.020 & 0.008 & -2.361 & 0.009 & -0.036 to -0.003 & -0.033 & -0.006 \\
\hline \multicolumn{9}{|l|}{ Sharp and Zantow (2005) } \\
\hline Shrimp & Price & 0.403 & 0.103 & 3.930 & 0.000 & 0.202 to 0.604 & 0.234 & 0.572 \\
\hline \multicolumn{9}{|l|}{ Tilley (2005) } \\
\hline Orange juice & Volume & -0.024 & 0.121 & -0.200 & 0.421 & -0.261 to 0.213 & -0.223 & 0.175 \\
\hline \multicolumn{9}{|l|}{ Carter (2005) } \\
\hline Frozen concentrated OJ & Volume & -0.008 & 0.004 & -1.952 & 0.025 & -0.016 to 0.000 & -0.015 & -0.001 \\
\hline
\end{tabular}

Notes: Interval estimates and p-values were calculated at a $95 \%$ level of confidence by the author from coefficients, standard errors, and t-statistics provided in each of the studies. Injury proxies that are expected to have an inverse relationship with the dependent variable are in italics. The one-tailed test is a test of whether the actual coefficient has the expected sign; positive when the subject import proxy is price or a profit margin and negative when the subject import proxy is volume. The two one-sided confidence intervals range from the 'greater than' value to $+\infty$ and from $-\infty$ to the 'less than' value with a $95 \%$ level of confidence.

${ }^{1}$ The proxy for injury (dependent variable) is the price of domestically produced good unless otherwise noted.

${ }^{2}$ The proxy for injury (dependent variable) is employment.

${ }^{3}$ The proxy for injury (dependent variable) is output. 
Simulations using point estimates for the 2002 cold-rolled steel antidumping investigation produced very different simulation results. Hausman (2002) found that the increase in the volume of subject imports between 1999 and $2001^{17}$ caused $41.2 \%$ of the decline in the price of US produced cold-rolled steel. On the other hand, Prusa (2002) found that the increase in the volume of subject imports between 1996 and $2001^{18}$ caused the average domestic price of cold-rolled steel to decrease by less than $\$ 1$ per ton or less than $1 \% .{ }^{19}$ Prusa (2002) also found that the decrease in the price of subject imports caused the price of domestically produced cold-rolled steel to fall by less than $\$ 3$ per ton during the same period. It is not surprising that their simulation results are different since each study defined imports of cold-rolled steel differently, specified different models, used different sample periods for model estimation, and used different time periods for their simulations. ${ }^{20}$

Table 2 compares the point estimates, standard errors, and change in imports used by Hausman (2002) and Prusa (2002) to simulate the impact of changes in the volume of subject imports. ${ }^{21}$ The point estimate for Prusa (2002) is much smaller than the one for Hausman (2002), although both are significantly different from zero at the $95 \%$ significance level. Table 2 shows that subject imports increase by more during the 1999 to 2001 timeframe than the 1996 to 2001 timeframe. The $75.7 \%$ increase in subject imports as defined by Hausman (2002) was a $1.7 \%$ decrease during the 1996 to 2001 timeframe used by Prusa (2002). The $0.5 \%$ increase in subject imports as defined by Prusa (2002) was a $88.1 \%$ increase during the 1999 to 2001 timeframe used by Hausman.

Table 3 shows that the probability that subject imports have a negative impact on the US price (p-value) is higher for each of the models when the 1999 to 2001 timeframe used by Hausman (2002) is applied. The probability of subject import volumes having at least some negative impact on the domestic price is $99 \%$ and $68 \%$ for the Hausman (2002) and Prusa (2002) models respectively when using the 1999 to 2001 timeframe, which decrease to $45 \%$ and $50 \%$ respectively using

17 More precisely, Hausman (2002) compared the periods November 1999 to March 2000 and April 2000 to May 2001.

18 More precisely, Prusa (2002) compared the periods 1996 to 1997 and 2000 to 2001.

19 Prusa (2002) calculated that the price of US produced cold-rolled steel fell by $\$ 110$ or about $23 \%$ between 1996 and 2001.

20 Prusa (2002) defines imports using four HTS categories, while Hausman (2002) uses a broader definition of 72 HTS categories. Between 1996 and 2002, imports of cold-rolled steel from subject countries as defined by Prusa (2002) was about $72 \%$ of the imports of cold-rolled steel from subject countries as defined by Hausman (2002). The sample used for estimation by Prusa (2002) was from May 1993 to April 2002, while the sample used for estimation by Hausman (2002) was from January 1993 to May 2001.

21 The following analysis is not necessarily the most appropriate simulation for these models, but a simple example to illustrate the importance of accounting for standard errors. Hausman (2002) uses a simulation that takes into account other variables in its model, but that simulation is not used here due to its complexity. Also, ideally the impact of prices of cold-rolled imports estimated by Prusa (2002) would also be incorporated into any simulation. 
Table 2. Estimated effect of subject import volumes on the domestic price of cold-rolled steel

\begin{tabular}{lrr}
\hline \hline & Hausman (2002) & Prusa (2002) \\
\hline Coefficient & -0.1573 & -0.0196 \\
Standard error of coefficient & 0.0518 & 0.0083 \\
Standard error of regression & 0.0224 & 0.0256 \\
Degrees of freedom & 87 & 98 \\
1999 to 2001 timeframe (used by Hausman (2002)) & & 88.1 \\
Percentage change of average subject imports & 75.7 & 0.6317 \\
Change in the natural log of average subject imports & 0.5640 & 0.0261 \\
Prediction error & 0.0368 & 0.5 \\
1996 to 2001 timeframe (used by Prusa (2002)) & & 0.0055 \\
Percentage change of average subject imports & -1.7 & 0.0256 \\
Change in the natural log of average subject imports & -0.0171 & 0.0224 \\
Prediction error & & \\
\hline \hline
\end{tabular}

Notes: ${ }^{1}$ Change in average subject imports between November 1999 to March 2000 and April 2000 to May 2001.

${ }^{2}$ Change in average subject imports between 1996 to 1997 and 2000 to 2001.

Table 3. P-value of subject imports having a negative impact on the price of cold-rolled steel

\begin{tabular}{lcc}
\hline \hline & Hausman (2002) & Prusa (2002) \\
\hline 1999 to 2001 timeframe (used by Hausman $(2002))^{1}$ & 99 & 68 \\
1996 to 2001 timeframe (used by Prusa $(2002))^{2}$ & 45 & 50 \\
\hline
\end{tabular}

Notes: ${ }^{1}$ Change in average subject imports between November 1999 to March 2000 and April 2000 to May 2001.

${ }^{2}$ Change in average subject imports between 1996 to 1997 and 2000 to 2001.

the 1996 to 2001 timeframe. Therefore, there is little evidence of a negative impact from subject imports using the 1996 to 2001 timeframe with both models, and at least some evidence of a negative impact with both models using the 1999 to 2001 timeframe.

Table 4 reports confidence intervals for the simulated impact of subject imports using estimates from both models and during both the 1996 to 2001 and 1999 to 2001 timeframes. Focusing just on the point estimate reported in the first column of the table, it seems that the Prusa (2002) estimate shows a very small impact from imports for both timeframes and the Hausman (2002) estimate shows a very small impact for the 1996 to 2001 timeframe and a much larger impact for the 1999 to 2001 timeframe. The two-sided confidence interval for the simulations using the Prusa (2002) model indicates that the impact varies from a $6 \%$ negative 
Table 4. Simulated impact of subject imports on the price of cold-rolled steel (percentage change)

\begin{tabular}{lcc}
\hline \hline & Point estimate & Interval estimate $^{1}$ \\
\hline Hausman (2002) & & -16.19 to -1.55 \\
1999 to 2001 timeframe & & \\
1996 to 2001 timeframe & & -8.19 to 5.04 \\
Prusa (2002) & -0.27 & -6.42 to 3.95 \\
1999 to 2001 timeframe & & -5.07 to 5.09 \\
1996 to 2001 timeframe & -1.24 & \\
\hline \hline
\end{tabular}

Notes: ${ }^{1}$ Two-sided $95 \%$ confidence interval estimate.

${ }^{2}$ Change in average subject imports between November 1999 to March 2000 and April 2000 to May 2001.

${ }^{3}$ Change in average subject imports between 1996 to 1997 and 2000 to 2001.

impact on price to a $5 \%$ positive impact on the price with $95 \%$ confidence. This implies that even using the 1996 to 2001 timeframe, the estimates suggest an impact of up to as much as $\$ 24$ per ton with $95 \%$ confidence, compared to the impact of less than $\$ 1$ per ton calculated from their simulation using only the point estimate.

The impacts also vary for the Hausman model, from about a $16.19 \%$ decline to a $1.55 \%$ decline for the 1999 to 2001 timeframe, and a $4.19 \%$ decline to a $5.04 \%$ increase for the 1996 to 2001 timeframe. If it is assumed that the point estimate of -8.87 represents an impact of $41.1 \%$ of the change in the price of cold-rolled steel, ${ }^{22}$ then the confidence interval indicates that subject imports of cold-rolled steel explain anywhere from about $7 \%$ to $75 \%$ of the change in the price for coldrolled steel.

It is clear that differences between the estimates from the two models are not due to inference as much as they are due to the difference in the estimated coefficients and time periods used in their simulations. However it is also true that relying entirely on the point estimates provides a false sense of precision.

\section{Conclusion}

Reporting confidence intervals and p-values provides a guide to the inferences that can be made from econometric models of injury. In some cases, estimates that are statistically significant provide more compelling evidence of a small impact than less precise estimates that are not statistically significant. Also, larger point estimates that are more precisely estimated can provide stronger evidence that the

22 It is assumed that results in the point estimate simulation done here represent a same percent of the change in the actual price as for the similar simulation done by Hausman (2002), since the actual decline in price is not provided by Hausman (2002). 
impact is small than estimates with smaller point estimates and larger standard errors. Accounting for the standard error will also provide a sense of how precise estimates are. In some instances this may indicate that any inference from the estimates is inconclusive, but in other instances it will provide additional confidence that the estimates are precisely estimated.

The ABA Section of Antitrust Law (2005) indicates that most useful econometric analyses do not reach definitive conclusions on the 'cosmic' issues such as defining the relevant market or determining if a merger is likely to be anticompetitive, but instead shed light on these 'cosmic' issues. ${ }^{23}$ Likewise, econometric models prepared for trade remedy investigations would have more of an impact on USITC determinations if they used confidence intervals and p-values to identify insights and data patterns important to injury analysis rather than attempting to make definitive conclusions about injury based on statistical significance.

\section{References}

ABA Section of Antitrust Law (2005), Econometrics: Legal, Practical, and Technical Issues, ABA Publishing.

Carter, Colin (2005), 'Economic Impact of FCOJ Prices of Imports of Certain Orange Juice from Brazil', exhibit 2 to 'Prehearing Brief of Sucocitrico Cutrale Ltda. and Louis Dreyfus Citrus Inc. - Certain Orange Juice from Brazil', Investigation No. 731-TA-1089 (Final), non-confidential version, 30 December 2005 (note: exhibit 2 is dated 28 December 2005).

Charles River Associates (2000), 'Econometric Analysis of the Effect of the Price of Subject Imports on the Price of Domestically Produced EPS', exhibit 11 to 'Certain Expandable Polystyrene Resins from Indonesia and South Korea/Pre-Hearing Brief on Behalf of BASF Corporation, Huntsman Expandable Polymers Company LC, Nova Chemicals Inc., and Styrochem US Ltd.', public version, 1 November 2000.

Grossman, Gene M. (1986), 'Imports as a Cause of Injury: The Case of the US Steel Industry', Journal of International Economics, 20: 201-223.

Hausman, Jerry A. (2001), 'Statement of Jerry Hausman', exhibit 4 of 'Pre-hearing brief on behalf of Bethlehem Steel, LTV Steel Company, Inc., National Steel Company, and US Steel LLC', public version', 12 September 2001.

Hausman, Jerry A. (2002), 'Technical Report: Cold-rolled Steel Products', an attachment to 'Certain Cold-Rolled Carbon Steel Flat Products from Argentina, Australia, Belgium, Brazil, China, France, Germany, India, Japan, Korea, Netherlands, New Zealand, Russia, South Africa, Spain, Sweden, Taiwan, Thailand, Turkey, and Venezuela: Joint Prehearing Brief of Nucor Corp., Steel Dynamics, Inc. WCI Steel, Inc. and Weirton Steel Corp.', public version, 12 July 2002.

Irwin, Douglas, A. (2003), 'Causing problems? The WTO review of causation and injury attribution in US Section 201 cases', World Trade Review, 2(3): 297-325.

Kelejian, Harry H. and Wallace E. Oates, (1981), Introduction to Econometrics: Principles and Applications, 2nd edn, Harper \& Row.

McCloskey, Deidre N. and Stephen T. Ziliak (1996), 'The Standard Error of Regressions', Journal of Economic Literature, 34 (March): 97-114.

Pindyck, Robert S. and Julio Rotemberg (1987), 'Are Imports to Blame? Attribution of Injury under the 1974 Trade Act', Journal of Law and Economics, 30 (April): 101-122.

23 ABA Section of Antitrust Law (2005), 116, 122-123. 
Prusa, Thomas J. (2001a), 'Quantifying the Factors Determining the Price of US Corrosion-Resistant Steel', 'Pre-hearing Brief on Behalf of Joint Respondent Producers in Argentina, Brazil, European Union, India, Japan, Korea, Russia, Taiwan, Thailand, and Venezuela: Carbon and Alloy Flat Products, Product 6 - Corrosion-Resistant and Other Coated Sheet and Strip in the matter of Steel', USITC Inv. No. TA-201-703, public version, 12 September 2001.

Prusa, Thomas J. (2001b), 'Quantifying the Factors Determining the Price of US Hot-rolled Steel Sheet', in 'Pre-hearing Brief on Behalf of Joint Respondents: Hot-Rolled Steel (Product Category A.3.), in the matter of Steel', USITC Inv. No. TA-201-703, public version, 12 September 2001.

Prusa, Thomas J. (2001c), 'Quantifying the Factors Determining the Price of US Cold-rolled Steel Sheet', Exhibit 4 in 'Pre-hearing Brief on Behalf of Joint Respondents: Product Group 4, Cold-Rolled Steel in the matter of Steel', USITC Inv. No. TA-201-703, public version, 12 September 2001.

Prusa, Thomas J. (2002), 'An Econometric Analysis of the Factors Determining US Producers' Price of Cold-Rolled Steel', an attachment to 'Joint Prehearing Brief of Respondents: Certain Cold-Rolled Carbon Steel Flat Products from Argentina, Australia, Belgium, Brazil, China, France, Germany, India, Japan, Korea, Netherlands, New Zealand, Russia, South Africa, Spain, Sweden, Taiwan, Thailand, Turkey, and Venezuela', Inv. Nos. 701-TA-422-425 and 731-TA-964-983 (Final), public version, 12 July 2002.

Prusa, Thomas J. and David C. Sharp (2001), 'Simultaneous Equations in Antidumping Investigations', Journal of Forensic Economics, 14(1): 63-78.

Rousslang, Donald J. (1988), 'Import Injury in US Trade Law: An Economic View', International Review of Law and Economics, 8: 117-122.

Sharp, David and Zantow, Kenneth (2005), 'Attribution of Injury in the Shrimp Antidumping Case: A Simultaneous Equations Approach,' Economics Bulletin, 6(5): 1-10.

Tilley, Daniel S. (2005), 'Factors Influencing FCOJ Futures Prices,' exhibit 2 to 'Submission of PostConference Brief and Answers to Commission Staffs Questions: Certain Orange Juice from Brazil, Investigation Nos. 731-TA-1089 (Preliminary), (on behalf of Louis Dreyfus Citrus SA, Louis Dreyfus Citrus, Inc., and Sucocitrico Cutrale Ltda.)', non-confidential version, 28 January 2005 (note: exhibit 2 is dated 17 January 2005).

US International Trade Commission (2005), Circular Welded Non-alloy Steel Pipe From China, USITC Publication 3807 (October).

US International Trade Commission (2007), Antidumping and Countervailing Duty Handbook, USITC Publication 3916 (April).

Ziliak, Stephen T. and Deidre N. McCloskey (2004), 'Size Matters: The Standard Error of Regressions in the American Economic Review', Journal of Socio-Economics, 33(5): 527-546. 